\title{
Abandono de estações férreas: cartografia nas cidades de Jaguarão e Rio Branco na fronteira Brasil-Uruguay
}

\author{
Abandono de la estación de ferrocarril: cartografía em las ciudades de \\ Jaguarão y Rio Branco en la frontera entre Brasil y Uruguay
Abandonment of railway station: cartography in the cities of Jaguarão and Rio Branco on the Brazil-Uruguay border

\author{
Vanessa Forneck ${ }^{1}$ \\ Eduardo Rocha ${ }^{2}$
}

\begin{abstract}
Resumo
Durante quase um século, as estações férreas funcionaram como ponto de embarque e desembarque de passageiros. Por volta de 1990 ocorre a interrupção de seu uso original e as edificações tornaram-se obsoletas e, por consequência, criaram-se territórios abandonados. Neste trabalho, busca-se explorar os territórios no entorno das estações férreas abandonadas, analisando as relações dessas edificações com quem habita aqueles espaços, compreendendo de que modo o local é sentido e vivenciado. O método adotado é o da cartografia sensível, onde são mapeados os processos vivenciados a partir de uma experiência em um território. As cidades-gêmeas de Jaguarão e Rio Branco apresentam a presença da ponte e da passagem do trem como indicadores de uma ação de ruptura, do atravessamento dessa linha de fronteira. Assim, as estações férreas possuíam uma força que atuava na conexão entre os países, e que hoje, não são mais encontradas. De forma simplificada, o abandono das estações férreas apresenta-se de duas maneiras. A primeira é um abandono visível, é estar nitidamente abandonada, sendo perceptível seus sintomas através de rachaduras aparentes, infiltrações, depredações. A segunda maneira é de um abandono invisível, oculto, que vai além da aparência material. As especificidades encontradas nesses territórios, auxiliam na elaboração de pistas que revelam as potencialidades que surgem a partir desses atravessamentos. Compreende-se o modo que as pessoas se apropriam das estações férreas e de que maneira podem ser propostas futuras intervenções nesses espaços, pensando na valorização da edificação patrimonial e nas novas dinâmicas encontradas nesses territórios.
\end{abstract}

Palavras-Chave: Abandono; cartografia sensível; estações férreas; fronteira Brasil-Uruguay; urbanismo contemporâneo.

\section{Resumen}

Durante casi un siglo, las estaciones de ferrocarril han funcionado como punto de embarque y desembarque de pasajeros. Alrededor de 1990 se interrumpió su uso original y los edificios quedaron obsoletos y, como resultado, se crearon territorios abandonados. En este trabajo, buscamos explorar los territorios alrededor de las estaciones de tren abandonadas, analizando las relaciones de estos edificios con quienes viven en esos espacios, entendiendo cómo se siente y se experimenta el lugar. El método adoptado es el de la cartografía sensible, en el que se cartografían los procesos experimentados a partir de una experiencia en un territorio. Las ciudades gemelas de Jaguarão y Rio Branco presentan la presencia del puente y el paso del tren como indicadores de una acción de ruptura, el cruce de esta línea fronteriza. Así, las estaciones de ferrocarril tenían una fuerza que actuaba en la conexión entre los países, y que hoy en día, ya no se encuentran. De forma simplificada, el

\footnotetext{
${ }^{1}$ Bacharel em Arquitetura e Urbanismo, mestranda em Arquitetura e Urbanismo na linha de Urbanismo Contemporâneo; Universidade Federal de Pelotas - UFPel; Pelotas, Rio Grande do Sul, Brasil; vanessaf.ufpel@gmail.com

${ }^{2}$ Doutor em Arquitetura e Urbanismo; Universidade Federal de Pelotas - UFPel; Pelotas, Rio Grande do Sul, Brasil; amigodudu@gmail.com
} 
abandono de las estaciones de ferrocarril se presenta de dos maneras. El primero es un abandono visible, es ser abandonado claramente, siendo percibido a través de aparentes grietas, infiltraciones, depredaciones. El segundo camino es un abandono invisible y oculto, que va más allá de la apariencia material. Las especificidades que se encuentran en estos territorios ayudan a la elaboración de pistas que revelan las potencialidades que surgen de estos cruces. Es comprensible que la gente se apropia de las estaciones de tren y cómo se pueden proponer futuras intervenciones en estos espacios, pensando en la valorización del edificio patrimonial y en las nuevas dinámicas que se encuentran en estos territorios.

Palabras claves: Abandono; cartografía sensible; estaciones de ferrocarril; frontera Brasil-Uruguay; urbanismo contemporáneo.

\begin{abstract}
For almost a century, the railway stations have functioned as the point of embarkation and disembarkation of passengers. Around 1990 its original use was interrupted and the buildings became obsolete and, as a result, abandoned territories were created. In this work, we seek to explore the territories around the abandoned railway stations, analyzing the relationships of these buildings with those who live in those spaces, understanding how the place is felt and experienced. The method adopted is that of sensitive cartography, where the processes experienced from an experience in a territory are mapped. The twin cities of Jaguarão and Rio Branco present the presence of the bridge and the passage of the train as indicators of a rupture action, the crossing of this border line. Thus, the railway stations had a force that acted in the connection between the countries, and that today, are no longer found. In a simplified way, the abandonment of railway stations is presented in two ways. The first is a visible abandonment, is to be clearly abandoned, being perceived through apparent cracks, infiltrations, depredations. The second way is an invisible, hidden abandonment, which goes beyond the material appearance. The specificities found in these territories help in the elaboration of clues that reveal the potentialities that arise from these crossings. It is understandable how people appropriate the railway stations and how future interventions in these spaces can be proposed, thinking about the valorization of the heritage building and the new dynamics found in these territories.
\end{abstract}

Keywords: Abandonment; sensitive cartography; railway stations; Brazil-Uruguay border; contemporary urbanism.

\title{
1. Introdução
}

O período ferroviário esteve presente no desenvolvimento urbano de diversas cidades do Brasil. A partir do século XIX, surge a proposta de instalação de uma malha ferroviária no Rio Grande do Sul, a fim de interligar o estado e também outras regiões do Brasil. A inserção da malha ferroviária era vista positivamente pelos moradores das cidades que recebiam a passagem do trem. Visto que contribuíam com uma série de melhorias, como na infraestrutura, no desenvolvimento econômico, na captação de recursos e no convívio social (IPHAE, 2002, p.18).

As estações férreas viraram ponto de encontros para as pessoas, otimizados pela chegada e partida de quem visitasse a cidade, assistido pelos olhos atentos dos moradores locais. A partir dos anos cinquenta, o cenário começa a mudar, sendo o sistema ferroviário substituído pelo rodoviário de forma gradual. Uma série de fatores políticos e econômicos contribuíram para a realidade deste cenário, como a baixa qualidade do serviço, o sucateamento da rede ferroviária, as tarifas elevadas e as constantes greves dos ferroviários (IPHAE, 2002, p.24). 
Diante da perspectiva de descaso com as malhas ferroviárias, cada vez mais, o sistema ferroviário perde seu espaço nas cidades. As estações férreas perdem seu sentido original, tornando-se abandonadas. Em seu entorno, criam-se ambientes que potencializam o aspecto do abandono. Muitas vezes manifestados através da destruição das estações, pela falta de manutenção, vandalismo, depredação, uma verdadeira incúria com o bem patrimonial.

De certo modo, os usos e atividades encontradas naquela ambiência refletem como as pessoas se sentem em relação ao abandono adjacente à estação férrea. Nesse sentido, o objetivo deste escrito é analisar os usos e sentidos encontrados no entorno das estações férreas, compreendendo como as pessoas se apropriam desses espaços, ou ainda, se são refutados, evitados. Busca-se perceber o sentimento gerado em relação ao abandono das estações férreas e de que modo é sentido, vivido e experienciado nos dias atuais. Para conseguir captar as relações do patrimônio edificado com as práticas cotidianas, utilizou-se o método cartográfico sensível. O objeto de estudo teve sua aplicação nas cidades de Jaguarão e Rio Branco na fronteira Brasil e Uruguay.

A cartografia é um procedimento desenvolvido pelos filósofos franceses Gilles Deleuze e Félix Guattari, que propõe mapear processos a partir de uma experiência. Como resultado compõe-se um mapa das sensações percebidas em um território, o que exige da cartógrafa uma atenção às sensibilidades que a cercam. A experiência inclui a ida à campo, que permite compreender como a apropriação do espaço é feita pelos indivíduos. Exige uma imersão no plano da experiência, podendo surgir pistas que revelem os sintomas desse abandono.

De maneira simplificada, o abandono pode ser percebido de duas maneiras: o primeiro é o abandono material, que remete às questões da própria estação férrea e suas condições físicas. O segundo é o abandono de sentido, relacionadas aos usos e as formas de ocupação desses espaços. Esses sintomas podem ser percebidos de duas maneiras, sendo ele visível, facilmente identificado ou de modo oculto, sendo possível de identificar a partir dos sinais descobertos. Assim sendo, as novas dinâmicas revelam e apontam a relação da população com as estações férreas e de que modo é sentido e vivenciado esse abandono. Revelando pistas de como a memória coletiva de uma sociedade é expressa na atualidade.

\section{O método cartográfico}

Cartografia se refere à mapas. Os mapas sempre estiveram presentes em nossas vidas, servem para comunicar, orientar, informar, representar uma porção no espaço, seja geográfico ou conceitual. A cartografia quer comunicar algo, podendo ser uma informação visual, 
sonora, tátil, sensitiva. A ideia é expressar uma realidade do mundo, que como qualquer forma de comunicação, pode apresentar distorções da realidade (ROCHA, 2008, p.164).

A primeira metade do século XX esteve marcada pela lógica modernista e pósmodernista, com as cidades direcionadas à perspectiva racional, funcionalista e sistemática. $\mathrm{O}$ modo de viver e o pensamento estavam voltados para a era industrial, assim ascendiam os centros urbanos principalmente com a migração dos moradores do campo para a cidade, que vinham em busca de melhores condições de vida. Além disso, o período vanguardista gerou grande influência para a área artística e cultural, que estavam voltados para o desenvolvimento econômico e social vigentes no novo século (ROCHA, 2008, p.165).

Com a vinda dos anos cinquenta, surgem novas ideias e maneiras de experimentar as cidades, indo além das propostas do funcionalismo moderno. Entram em ação os situacionistas $^{3}$, que fazem duras críticas às concepções ideológicas e estruturais do espaço urbano moderno. Os situacionistas apoiavam a construção da cidade de forma coletiva, em que os próprios atores que compõe a sociedade, devessem fazer parte do processo. Eram contrários aos monopólios urbanos dos urbanistas e planejadores. Lutavam e reivindicavam por políticas urbanas que possibilitasse maior diversidade e qualidade de vida aos usuários (JACQUES, 2003).

Em contrapartida, o que se propõe nesta pesquisa é uma cartografia complementar, visando a experimentação de novas formas de analisar os espaços urbanos. Tem como princípio a filosofia da diferença ${ }^{4}$, proposta pelos filósofos franceses Gilles Deleuze e Félix Guattari. Se difere dos mapas tradicionais que apresentam uma leitura estática de cidades e de modelos preestabelecidos.

A cartografia é uma forma de investigação que propõe mapear um processo, contrariando a ideia da representação de um objeto. Desassemelha-se de um mapa urbano que apresenta ruas, quarteirões, prédios, praças, cursos d'água. A cartografia compreende um conjunto de sensações motivadas a partir de uma experiência, que resultam na composição de um mapa. É o mapa do que é sensível, do heterogêneo, das particularidades que são vistas e vividas em um território, mas na maioria das vezes, não são faladas.

\footnotetext{
${ }^{3}$ Os situacionistas surgem em Londres em 1957. Foi um movimento internacional de cunho sociopolítico e artístico fundado por Guy Debord, filósofo francês. Com o intuito de questionar e criar "situações" que conduzisse à participação da população, através da arquitetura e do espaço urbano, para promover uma revolução na vida cotidiana, contrária à alienação e passividade da sociedade.

${ }^{4}$ A Filosofia da diferença enaltece uma realidade de mundo a partir de novos ângulos, onde busca dar voz à diferença, com base numa perspectiva de nova imagem do pensamento (Gilles Deleuze).
} 
A proposta é observar as dinâmicas a partir de uma perspectiva que aproxime o campo do observador com o observado, criando uma aproximação do plano da experiência. Propondo a descoberta de um território que caminha pelas frestas da cidade, nos lugares não comuns, que revelam acontecimentos minorizados e invisibilizados pelos mapas hegemônicos. Estes mapas apresentam uma releitura da paisagem, das cenas cotidianas, que vão além do aspecto físico e horizontal. Pensando uma realidade de mundo rica e complexa a partir dos processos de transição e transversalidade (ROCHA, 2008, p.168).

O mapa é formado de modo adaptável, onde pode ser invertido, rasurado, rasgado, reinventado. Pode ser sobreposto e reconectado a outros mapas, por isso, entende-se como mapa cartográfico sempre estar aberto e suscetível a constantes modificações. Não há regras ou um manual de composição, pode ser feito individualmente ou em grupos, adaptável a cada caso. Entende-se essa adaptabilidade na cartografia com o conceito de rizoma proposto por Deleuze e Guattari (2011), onde não há um começo, nem um fim. As múltiplas forças que atuam no plano da experiência podem ser conectadas, não havendo uma hierarquia ou linearidade dos componentes. As distintas potencialidades subjetivas que atuam nos territórios existenciais, tecem uma malha munida de múltiplas forças, sendo essas forças capazes de provocar o processo de criação (DELEUZE \& GUATTARI, 2011, p.33).

A cartografia tem caráter qualitativo, onde o que importa são as intensidades das informações e as potencialidades provocadas naquele momento. A experiência de cada indivíduo é única e possui uma singularidade em seu processo. Não há espaço para a neutralidade por parte da pesquisadora, pois exige uma imersão no plano da experiência, que traz à tona reflexos políticos e sociais na produção do conhecimento (PASSOS; KASTRUP; ESCÓSSIA, 2015, p.30).

\subsection{Procedimentos metodológicos}

Os procedimentos adotados para a realização do trabalho consistiram, primeiramente, na programação da viagem para as cidades de Jaguarão e Rio Branco, ocorrida nos dias 27 e 28 de novembro de 2019. A pesquisa propõe intervenção, há a aproximação entre o sujeito e o objeto cartográfico, entre teoria e prática. A constituição de dado objeto é conhecida caminhando com esse objeto, constituiu-se no caminho, não há como conhecer uma realidade sem estar imerso no plano da experiência (PASSOS; KASTRUP; ESCÓSSIA, 2015, p.31).

Os demais processos metodológicos são o diário de campo, que consiste na prática de registros, escritas, desenhos que colaboram na produção de dado de uma pesquisa, transformando-os em conhecimento e modos de fazer, e os registros fotográficos que visam a 
captura dos momentos vividos durante a experiência. Numa perspectiva construtivista, não há uma "coleta de dados", estudos recentes afirmam que o que ocorre é uma produção de dados da pesquisa, pois existe uma real produção no plano da experiência, que já se encontrava lá antes mesmo da pesquisa (PASSOS; KASTRUP; ESCÓSSIA, 2015, p.33).

\section{A fronteira Brasil-Uruguay | as cidades de Jaguarão e Rio Branco}

A fronteira Brasil-Uruguay viveu constantes disputas territoriais, de um lado o Brasil, colonizado pelo império português e do outro o Uruguay, território pertencente à Espanha. Os países estabeleceram diversos acordos, entretanto o descumprimento frequente ocasionava constantes episódios de conflitos e guerras acerca da disputa territorial. Paralelo às questões territoriais, a região da fronteira era provida da criação bovina e, mais adiante, fomentada com a produção do charque. Com a emancipação das colônias espanholas, os charqueadores tiveram o livre acesso pelo Rio da Prata, facilitando o escoamento da mercadoria através da malha ferroviária, até chegar ao porto de Montevideo (IPHAN, 2010, p.42).

A implantação da malha ferroviária teve um papel importante no desenvolvimento econômico e social no Estado. O primeiro trecho a ser consagrado com a passagem do trem foi a zona de colonização alemã, localizada no vale médio dos Sinos, considerada o "celeiro da Província”. A ferrovia foi construída pela Porto Alegre \& New Hamburg Railway Company Limited, sendo uma ligação importante com a capital Porto Alegre. Além dessa, havia mais quatro linhas principais de ferrovias, conforme apresentado na Figura 1 (IPHAE, 2002, p.19).

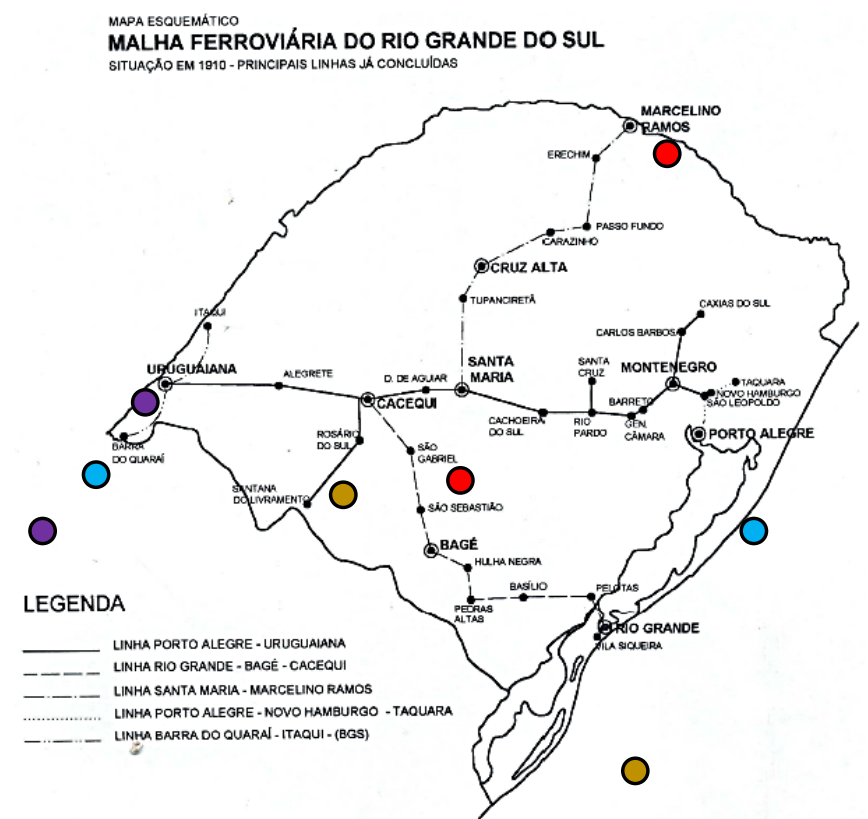

Figura 1: Mapa da malha ferroviária do Rio Grande do Sul em 1910. Fonte: IPHAE (2002, p.23). Adaptado pela autora. 
Inicialmente, a Estrada de Ferro Porto Alegre - Uruguaiana tinha um objetivo mais estratégico do que econômico, pois conectava Porto Alegre e a fronteira oeste. O surgimento da linha da Estrada de Ferro Rio Grande - Bagé ocorreu paralelo às fronteiras com o Uruguay. Na época cortava a região mais próspera do Estado, sendo o principal motivo econômico a criação do gado, fundado no tripé porto-charque-gado. Já a Estrada de Ferro Santa Maria - Marcelino Ramos conectava o centro com o norte do estado. O governo imperial concedeu ao Engenheiro João Teixeira Soares que realizasse a construção de uma estrada de ferro que ligasse o Rio Grande do Sul a São Paulo, o início partiria das margens do Rio Itararé, na divisa entre Paraná e São Paulo, chegando até Santa Maria. Por fim, a Estrada de Ferro Barra do Quaraí - Itaqui recebeu a construção de uma estrada na fronteira oeste do Estado, partindo da margem direita do Rio Quaraí até a Vila de Itaqui (IPHAE, 2002, p.1921).

De acordo com o Inventário das Estações Férreas 1872-1959, elaborado pelo Instituto do Patrimônio Histórico Estadual - IPHAE, no ano de 2002, Jaguarão pertencia à Linha Rio Grande-Bagé-Cacequi/Ramal Basílio-Jaguarão. A estação férrea foi inaugurada em 25/03/1932 e desativada na década de oitenta. Construída pelo $1^{\circ}$ Batalhão Ferroviário, é caracterizada como estação de médio porte, com projeto padrão da VFRGS (Viação Férrea do Rio Grande do Sul) nas décadas de trinta e quarenta. Apresenta cobertura inclinada com múltiplas águas e beirais largos, as esquadrias do pavimento inferior apresentam vãos com verga em arco abatido e no pavimento superior com verga reta, conforme mostra a Figura 2 (IPHAE, 2002, p.96).

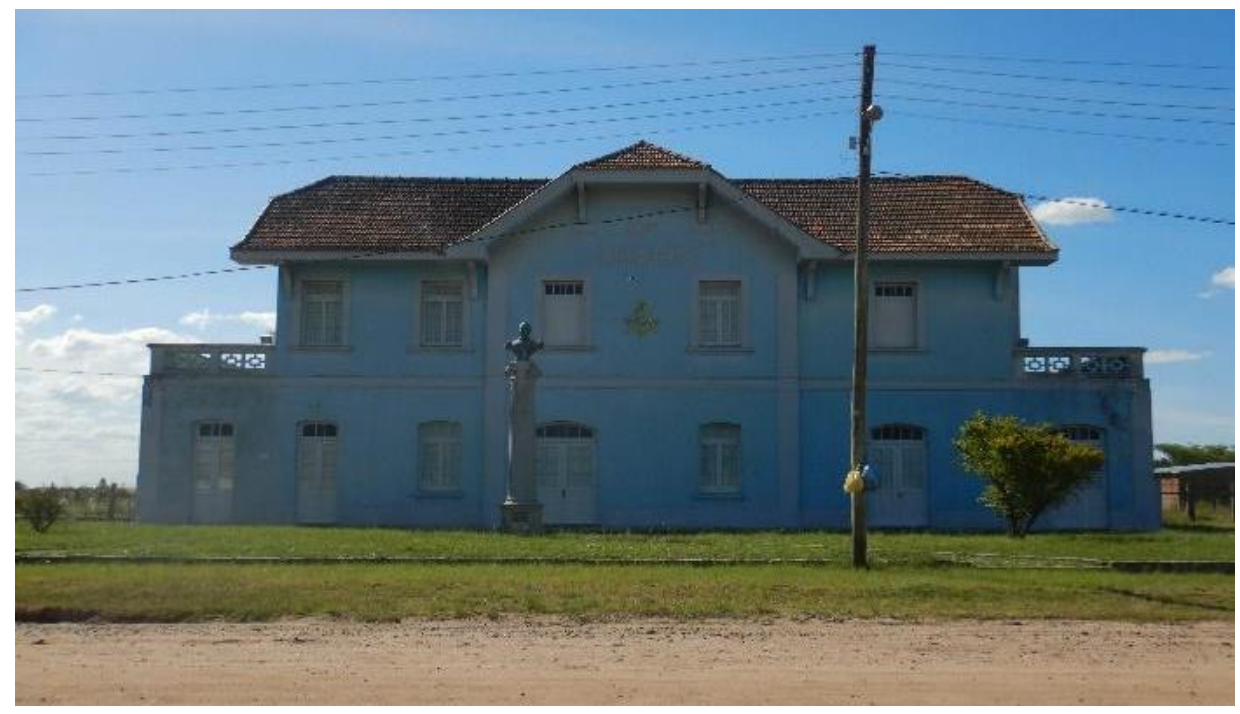

Figura 2: Estação férrea de Jaguarão, Brasil.

Fonte: Acervo da autora, 2019. 
A estação férrea se encontra na região noroeste da cidade, fora do centro histórico e distante do Rio Jaguarão, rio que faz divisa com o país vizinho Uruguay. As atividades econômicas que contribuíram para o desenvolvimento e consolidação de Jaguarão estavam baseadas na questão militar, na produção do gado e na comercialização de mercadorias. $\mathrm{O}$ início da consolidação urbana ocorre às margens do rio Jaguarão, local de intensificação comercial, estimulada pela presença da tropa. O traçado urbano é disposto de modo ortogonal, com ruas e quarteirões de tamanhos variados. A retícula de assentamento com características militares, ordena e prevê a expansão urbana de Jaguarão, apesar de regiões mais periféricas não seguirem o mesmo traçado reticulado (MARTINS, 2001, p.65).

Em relação à linha ferroviária de Rio Branco, no Uruguay, há pouco material disponível, incluindo dados sobre a estação férrea. Foram encontradas algumas informações no memorial exposto na parede da própria estação. A estação denominada como Ferrocarril Treinta y Tres - Rio Branco foi finalizada em 1936. Sob responsabilidade da Empresa Constructura Uruguaya "A.S.S.M" Ingenieros y Contratistas aliada com Walter Scott \& Middleton Ltd Y Anglo Scottish Construction $C^{o}$ Ltd de Londres. A seguir, a Figura 3 apresenta o registro da estação.

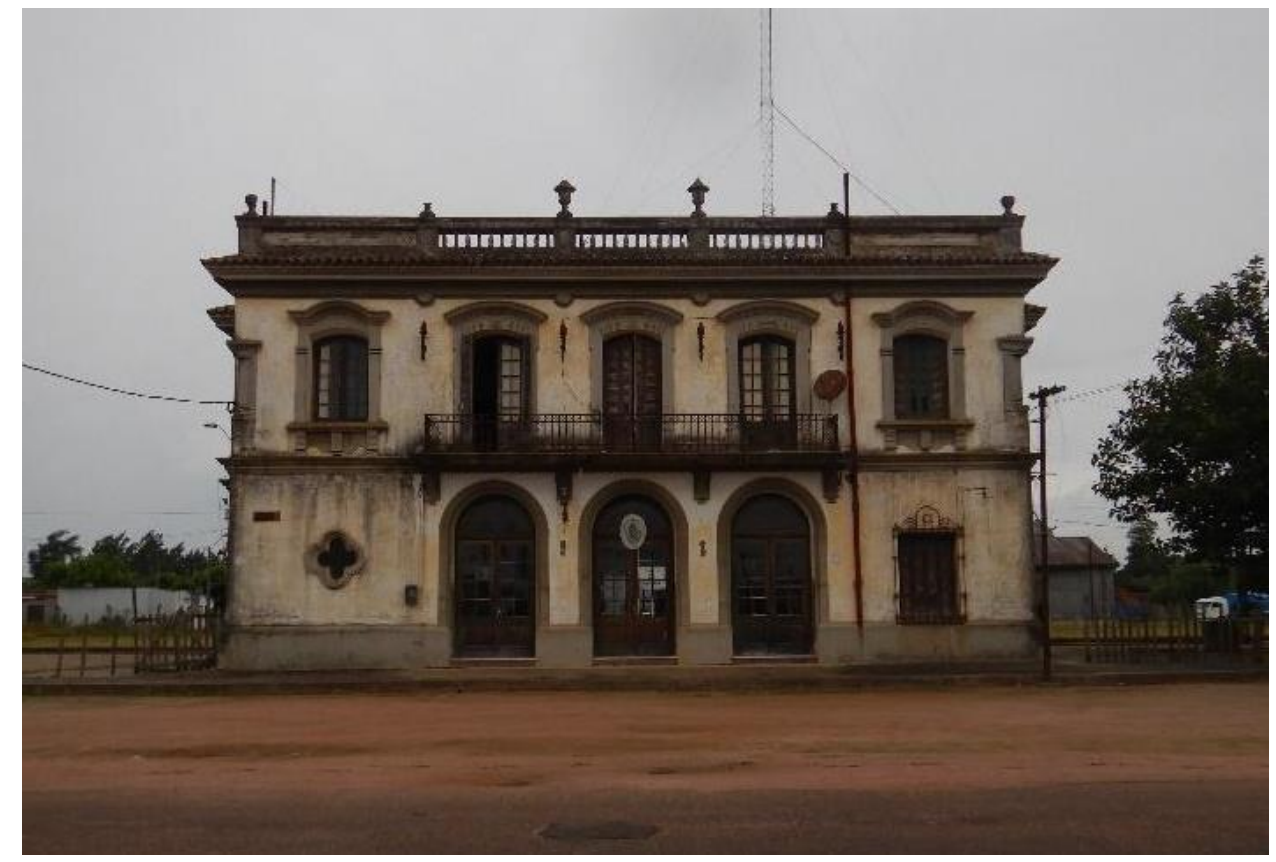

Figura 3: Estação Férrea de Rio Branco, Uruguay.

Fonte: Acervo da autora, 2019.

A edificação possui dois pavimentos, com construção em alvenaria. As tipologias dos vãos são variadas, as três portas do acesso principal e uma porta na fachada posterior possuem verga em arco pleno. As demais portas aos fundos possuem verga reta, como também as aberturas na fachada lateral e uma janela na fachada principal. Os vãos das aberturas no 
pavimento superior são com verga em arco abatido. A cobertura possui platibanda e aos fundos possui uma cobertura aparente em uma água na antiga área de embarque e desembarque de passageiros 5 .

O início da ocupação de Rio Branco ocorre por volta de 1792, quando são instaladas três guardas no cerro Juncal, localizado às margens do atual território brasileiro. Em 1801, com o avanço dos portugueses, a guarda é transferida para a região sudoeste, dando início ao pequeno povoado, conhecido por Guarda de Arredondo, depois chamado de Pueblo de Arredondo. Em 5 de julho de 1853 é aprovada uma lei que dá o nome de Artigas para o povoado, iniciando a regularização e ampliação urbana. A localização ocorre às margens do Rio Jaguarão, uma região mais baixa exposta às frequentes cheias do rio. Quando em 1888 ocorre uma cheia que alaga a metade da cidade, inicia a formação de outro núcleo em uma região mais alta, chamada "la Cuchilla". A urbanização se expande na região mais elevada da cidade, resultando em uma formação linear e descontínua (MUSSO, 2004, p.247).

As cidades de Jaguarão e Rio Branco estão conectadas pela Ponte Internacional Barão de Mauá finalizada em 1930. Sua construção foi destinada para o transporte rodoviário e ferroviário, quando então se constrói o ramal de Treinta y Tres, com uma estação no bairro $L a$ Cuchilla e outra no núcleo antigo junto à ponte. Em 1998 são estudadas propostas da construção de uma nova ponte internacional, prevista em outra localização. As condições estruturais da ponte atual já não suportam o tráfego pesado e ferroviário, sendo necessário o novo empreendimento (MUSSO, 2004, p.289). Até o momento, a proposta não se consolidou. Em ambas cidades o transporte ferroviário foi interrompido por volta do ano de 1980, atualmente o transporte de caminhões pesados ainda é feito pela Ponte Internacional existente.

\subsection{A situação atual das estações férreas}

O sistema de transporte ferroviário teve seu auge marcado no período de 1874 até o final da década de 1950, fase em que o transporte ferroviário começa a ser substituído pelo modelo rodoviário. A substituição foi feita de maneira gradual, com a extinção contínua de trechos de viagens de passageiros. No Rio Grande do Sul, por volta da década de 1990, a Rede Ferroviária Federal S/A - RFFSA foi incluída pelo Programa Nacional de Desestatização, criado pelo governo Collor.

Em 1996, a malha sul, formada pelas linhas que conectavam os estados do Rio Grande do Sul, Santa Catarina e Paraná, foram leiloadas e arrendadas pela Ferrovia Sul Atlântico, depois América Latina Logística - ALL, destinada à logística de transporte de carga (IPHAE,

\footnotetext{
${ }^{5}$ Considerações feitas pela autora, com base no material do IPHAE, 2002.
} 
2002, p.13-14). No ano de 2015, a ALL se integrou com a Rumo logística, com sede em Curitiba - PR, sendo hoje a concessionária que administra mais de 12 mil quilômetros de malhas ferroviárias no Brasil.

A decadência do transporte ferroviário foi se debilitando ao longo dos anos. Um dos fatores foi o período marcado pela fragilidade política, principalmente dos países envolvidos com a $1^{a}$ Guerra Mundial. Ocorreram maiores demandas do transporte para a exportação, endividamento belga e a substituição das ações ferroviárias do Rio Grande do Sul por empresas norte-americanas (IPHAE, 2002, p.24). Assim, aos poucos o transporte ferroviário perde força e a substituição para o transporte rodoviário aumenta, otimizados pelos fatores que envolvem os poucos investimentos na rede e pelas estratégias políticas e econômicas do mercado.

Com a extinção do transporte de passageiros, as estações férreas perderam seu uso original. Muitas delas se encontram em estado de abandono, sendo visível a falta de cuidado e atenção com essas edificações que possuem valor histórico e cultural. Com a inexistente ou escassa verba destinada à sua conservação, as estações férreas ficam expostas às intempéries e aos atos de vandalismo, como depredação da edificação, supressão de elementos construtivos, como portas e janelas e também a retirada de ornamentos. Ainda, temos o fator temporal que incide em toda e qualquer construção, sendo imprescindível a manutenção constante para prolongar a vida útil de uma edificação.

O abandono material relacionado às condições físicas da edificação, não é o único manifestado como um abandono. Existem nas estações férreas outros tipos de abandono, como o abandono do uso, o abandono da função, o abandono do sentido. Este tipo de abandono apresenta fatores mais complexos, envolvendo um conjunto de subjetividades que perpassam as circunstâncias materiais. Esse tipo de abandono exige um olhar mais atento e sensível às diferentes formas de atuações encontradas naquela ambiência.

O abandono é disposto como momentâneo, o registro foi feito naquele instante, numa determinada hora, num determinado dia. Amanhã pode não estar mais daquela maneira, pode ruir e desabar a edificação. Pode ter um projeto de revitalização, uma ocupação, uma intervenção que transforme o lugar completamente, entre outros fatores. O abandono não é estático, ele é um estado identificado naquele instante, que está em constante transformação. O que hoje é abandono, amanhã pode não ser mais. 


\section{Sintomas do abandono}

Os sintomas do abandono das estações férreas são manifestados de diversas maneiras. Não há uma classificação ou predefinição, no entanto há um esforço para dar visualidade no que tange o abandono relacionado com o patrimônio edificado. Desta forma, a síndrome do abandono, ou "abandonnique"6 apresenta algumas características próprias em sua manifestação.

Dentre tantos sentimentos que poderiam se enquadrar aqui, há dois pontos que são caracterizados como típicos da síndrome do abandono: a angústia e a agressividade. Os dois estão relacionados a um estado caracterizado pela ausência de um justo sentimento de ego e de seu valor próprio. Ocorre o encadeamento da angústia ao se deparar com o abandono, da agressividade que faz brotar e da resultante não-valorização que abarca toda a sintomatologia desta forma de neurose (GEUX, 1973, p.30).

A angústia apresenta diversas intensidades, indo de um estado singelo de mal-estar, passando para um estado intenso de angústia, que retoma e faz surgir o espectro da ausência de amor e de solidão (GEUX, 1973, p.30). Ao se deparar com um prédio abandonado, o indivíduo pode apresentar um sentimento de aflição pela condição da edificação. É um sentimento que surge naquele instante, à primeira impressão, é um incômodo, um desconforto ao se deparar com a obra naquela condição. Porém, quando o indivíduo se afasta do local, o sentimento de angústia desaparece, retornando ao seu estado habitual. Por outro lado, há o extremo do sentimento provocado pela angústia, onde o indivíduo vê o abandono de maneira dolorosa, fica exposto à falta de cuidado, de amor, indo além de um simples desconforto visual. Essa angústia ao extremo, pode afetar o indivíduo de tal forma que desencadeie em sua própria vida o sentimento de abandono. O abandono da edificação provoca nele um sentimento intenso, que o incomoda profundamente, permanecendo o sentimento ruim/negativo mesmo sem permanecer no lugar.

Assim como a angústia, outro sentimento ocasionado pela síndrome do abandono é a agressividade. Apresenta-se de diversas formas e intensidades, explícito ou oculta, instantânea ou retardatária, sádica ou contida, entre outros fatores. Geralmente, o motor agressivo é manifestado ativamente no indivíduo, nos seus atos, pensamentos e sentimentos (GEUX, 1973, p.32-33). A agressividade gerada através de uma edificação abandonada, pode despertar um sentimento tão intenso que tudo se torna pretexto para reivindicação, ali podem ser

\footnotetext{
${ }^{6}$ O termo "abandonnique" criado por Germanie Geux, designa uma pessoa que se sente abandonada ou que vive no temor do abandono. É um estado psíquico dominado pela angústia do abandono, e não a de um fato familiar e social que tenha, obrigatoriamente, uma realidade objetiva.
} 
descontadas frustrações, satisfazer seus rancores, vingar acontecimentos do passado. Assim, as edificações são depredadas, danificadas, sucateadas, saqueadas, esquecidas e abandonadas. Não há amor, só sentimento de perda e solidão, enunciadas por uma necessidade de retaliação.

No entanto, deve-se estar atento aos sinais do abandono. $\mathrm{O}$ edifício abandonado pode apresentar parede rachada, descascada, uma porta ou janela faltando, telhas quebradas, sujeira acumulada, teias de aranhas, esses são todos sinais que projetam exteriormente o indício do abandono. Porém, o abandono pode se manifestar de maneira tênue, menos externalizada. As edificações abandonadas podem se revelar através de lacunas da inutilidade, da fraqueza, da incapacidade de serventia, mesmo que passageira. É o abandono da função, do sentido. A estação férrea não serve mais, não está em função. Logo, tudo o que está na condição de aguardo, de certa forma está abandonado (ROCHA, 2010, p.147).

Passando para um pensamento mais filosófico, pensar o abandono ali presente, só existe devido a obra arquitetônica que resiste à tempestade violenta em que é envolvida. A paisagem natural, seu brilho, sua obscuridade, as vidas que ali se manifestam, não eram inexistentes ou invisíveis, "o que a obra templo opera é precisamente o seu aparecer como tais, como vida, como brilho, como quietude, como violência” (SARAMAGO, 2008, p.196). É com base na estação férrea que seu entorno não é visto apenas como reserva material disponível, mas sim, na sua plenitude de seu ser em si próprio.

O abandono da estação férrea faz ver o céu nublado recortado pela edificação, faz ouvir o cantarolar dos pássaros, ver o animal que se abriga da chuva, o florescer da vegetação, a força do vento. Por si só, a matéria não é obra "natural”, nem mesmo pertencente ao mundo. Entretanto, a partir da terra, que a materialidade da existência se revela em seu brilho, na nitidez ressaltada na natureza, na invisibilidade do ar que se permite ver. É a manifestação do invisível que se faz refletir no que é visível e palpável do mundo (SARAMAGO, 2008, p.197).

\section{Resultados e discussões}

As cidades de Jaguarão e Rio Branco apresentam uma fronteira molhada, ou seja, são divididas pelo rio Jaguarão. Uma característica em comum entre elas é a ligação pela ponte, chamada de Ponte Internacional Barão de Mauá, local onde também passava o trem. A ponte é um elemento imponente que estabelece um conjunto de forças integrando Brasil e Uruguay. Ela apresenta uma relação de atravessamento, de cruzar, transgredir um território, fato que acompanhou o período histórico desta fronteira. A ponte conecta um território a outro, faz uma interlocução, dá acesso, cria uma articulação e relacionamento entre os dois países. Por 
outro lado, a ponte também causa um sentimento de hostilidade, pois ali é território neutro, incerto. Não pertence a nenhum lado, é o entre-lugar, aquele que divide, delimita, refuta e segrega.

Nesse sentido, pode-se pensar nesse atravessamento da linha férrea, este que cruza a fronteira. Há uma conexão estabelecida pela linha férrea entre os países, onde circulavam mercadorias para serem comercializadas e na travessia do trem de passageiros em busca de outros destinos. Era uma relação intensa, desse ir e vir pela fronteira, que pulsava, fazia parte da economia. Uma relação econômica, política, social e cultural que se entrelaça.

As estações férreas eram como "pontes" que conectavam esses territórios, atuavam como ponto de encontro. O local onde era feito o carregamento de mercadorias, das chegadas e partidas de pessoas de diferentes lugares e culturas, um ponto que movimentava a cidade. $\mathrm{O}$ trem rompia com a delimitação de fronteira, pois o atravessamento era trivial. Pensar na linha do trem nos dias de hoje, tem outro significado. Já não há a mesma relação com as estações férreas, os usos mudaram, não se sente mais o local como antigamente. Nesse sentido, buscou-se percorrer o trajeto da linha férrea até as estações de Rio Branco e de Jaguarão, para analisar as dinâmicas encontradas nesses "novos" territórios.

\subsection{Estação Férrea de Rio Branco, Uruguay}

No dia 27 de novembro de 2019, o tempo estava nublado e com risco de chuva. Havia disposição e curiosidade, a busca por uma experiência num caminho desconhecido. Percorrer pelos trilhos até a estação férrea de Rio Branco no Uruguay. O caminho era longo, era preciso energia e atenção para perceber os atravessamentos sentidos durante o trajeto. Na maior parte da caminhada a vegetação tomava conta dos trilhos, alguns trechos difíceis de serem percorridos. Cavalos pastando naquele entre espaço. O lugar de cruzar, pular os trilhos, atravessar de uma área da cidade para outra. A linha férrea cortava a cidade, haviam moradores caminhando por ali. Próximo à estação férrea, dois jovens sentados no local do antigo embarque e desembarque de passageiros (Figura 4). 


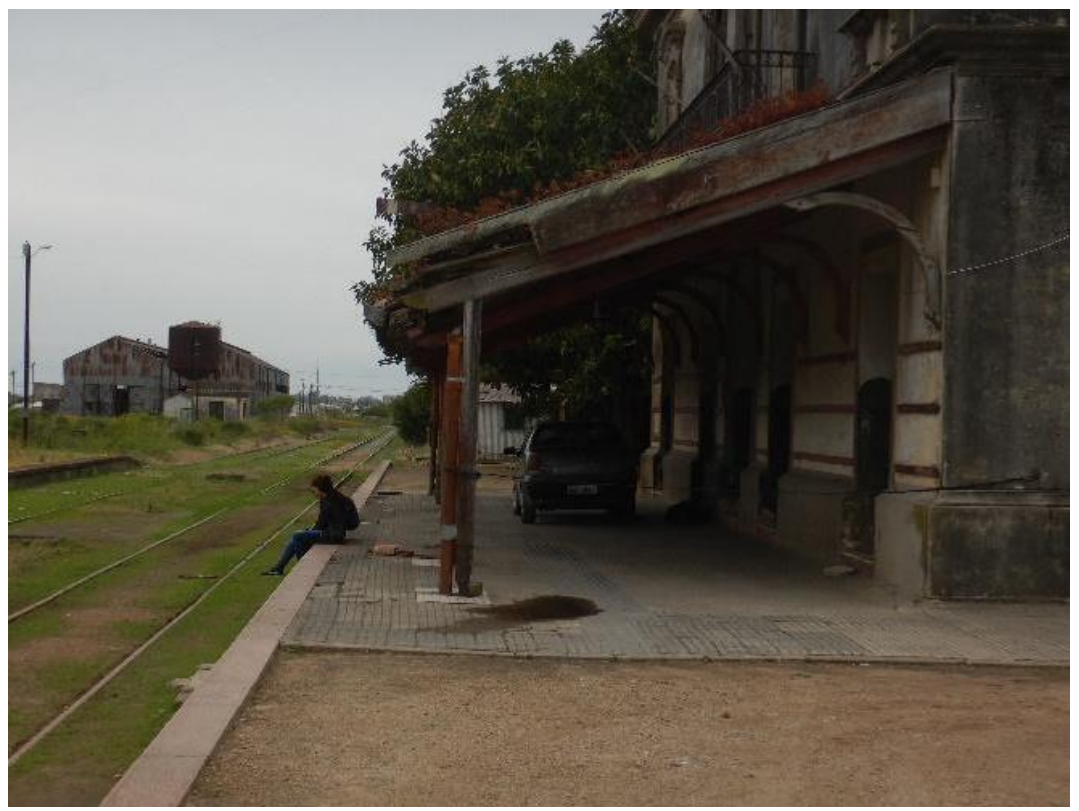

Figura 4: Dois jovens junto à estação férrea de Rio Branco, Uruguay.

Fonte: Acervo da autora, 2019.

Os dois jovens aparentavam ter quinze anos, com mochilas nas costas, sentados e conversando. Logo acima um telhado com a estrutura comprometida, uma parte destruída e o madeiramento apodrecido já demonstrava sinais de alerta. A cobertura não estava segura, havia uma corda em todo o perímetro, uma barreira de contenção para não ser ultrapassada. Apesar da barreira, havia um veículo estacionado embaixo.

O cenário constituído pelo som dos pássaros, o vento forte, uma chuva fraca começa a cair. Havia uma indústria localizada a 500 metros, o som dos motores ecoava pelo ar. Segue sendo um local de passagem, pessoas passando pela lateral da estação e cruzando os trilhos em direção ao outro lado da cidade. O olhar atento aos detalhes da estação férrea, o estado visível de um abandono. O telhado quebrado, vegetação crescendo em cima, madeira apodrecida, algumas janelas danificadas, parede com sujidade e mofo (Figura 5).

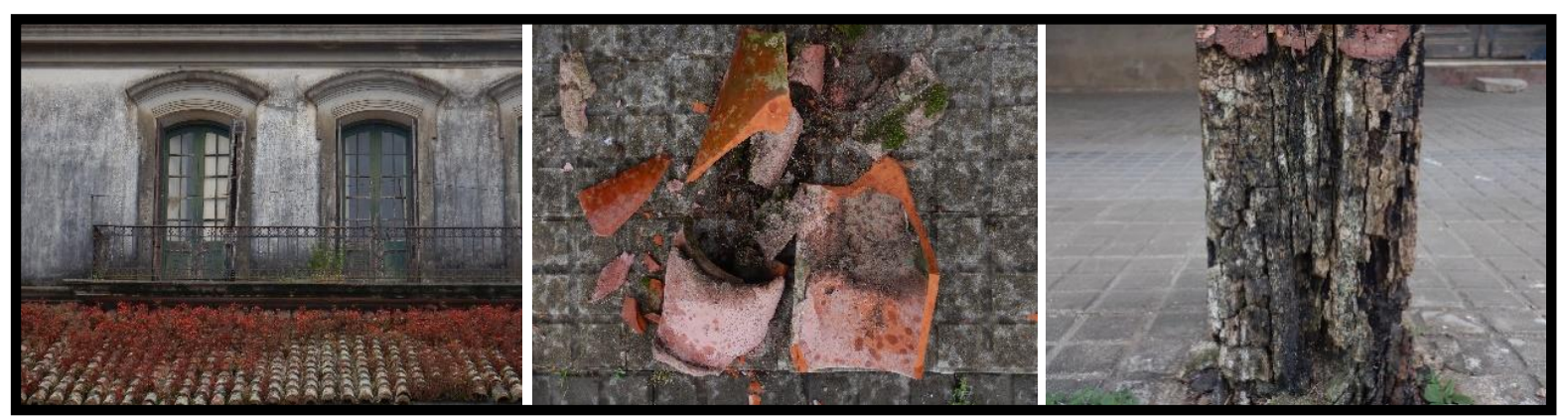

Figura 5: Conjunto de imagens do abandono visível da estação de Rio Branco.

Fonte: Acervo da autora, 2019

Era perceptível a necessidade de manutenção, estava explícito o estado de abandono em que se encontrava a edificação. Em um olhar mais atento, uma luz vinha de dentro do 
prédio no pavimento superior. Uma janela aberta. Pela porta de acesso dava para enxergar uma moto dentro da estação e uma campainha instalada na fachada frontal. Indícios de um abandono que não estava abandonado. Aparece um senhor na janela, aproximadamente uns sessenta anos, era ex chefe da estação e morador há 39 anos. Esse senhor zelava e cuidava da estação férrea nas condições que conseguia. O transporte de passageiros havia sido interrompido há mais de vinte anos, a falta de manutenção e o estado de abandono eram visivelmente percebidos, entretanto o lugar não estava abandonado.

\subsection{Estação Férrea de Jaguarão, Brasil}

No dia 28 de novembro, o tempo estava quente e com sol. O caminho percorrido era em direção à estação férrea de Jaguarão. Os vestígios dos trilhos estavam escassos, haviam sido encobertos para receber nova pavimentação no canteiro central de uma avenida. Entre um cruzamento e outro da avenida viam-se os trilhos no asfalto, que retornando para o canteiro, ficavam encobertos novamente.

No fim do canteiro os trilhos faziam uma curva para a direita. Ficava cada vez mais difícil de ser localizado. As casas invadiram a linha férrea e em alguns trechos os trilhos haviam sido removidos. Os moradores cercavam o terreno, deixando o acesso ainda mais dificultado. Era preciso invadir lotes, pular cercas, para caminhar pelos trilhos. Parte do trajeto foi contornada, a outra parte, violada. Próximo à estação férrea, havia uma grande área cercada, aproximadamente o que contemplava todo o sítio ferroviário. Apenas a fachada da frente não estava cercada (Figura 6).

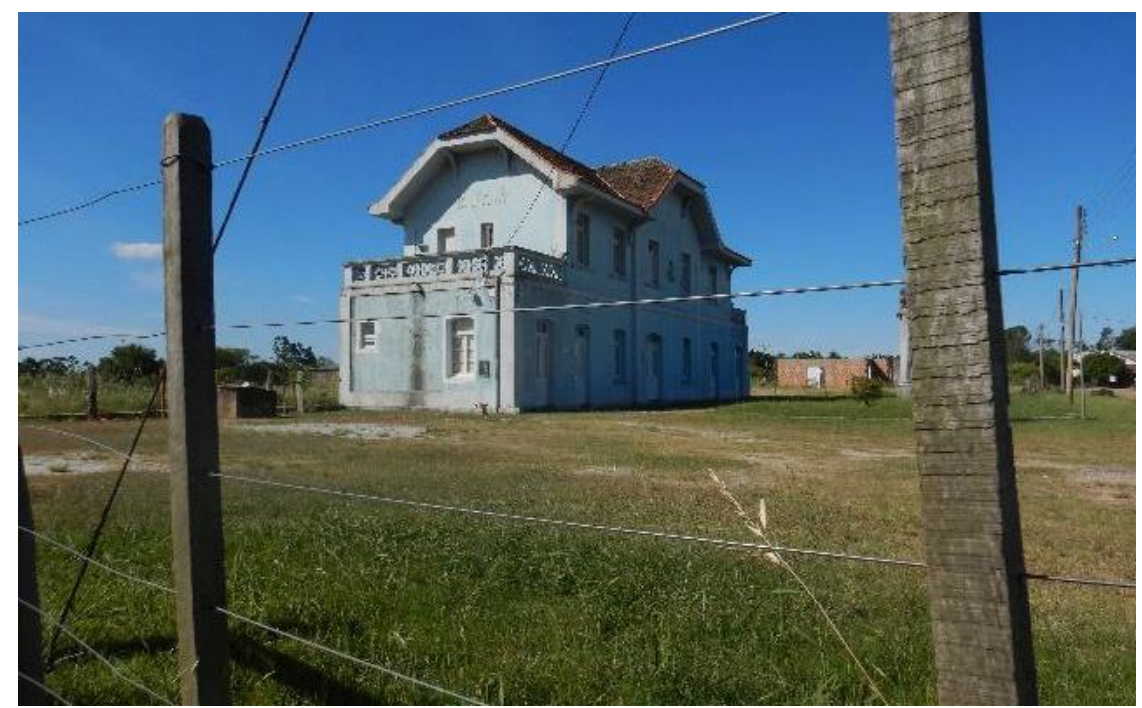

Figura 6: Cerca na lateral da estação férrea de Jaguarão, Brasil.

Fonte: Acervo da autora, 2019.

Invadir, transgredir um território, pular uma barreira para seguir o caminho dos trilhos. O sentimento que havia naquele momento era o de alerta, atenção. A estação estava fechada. 
As paredes pintadas, esquadrias bem conservadas, nos fundos havia a instalação de arescondicionados na edificação, uma câmera de vigilância e ao lado uma placa indicando que o lugar estava protegido. Não havia indícios do abandono material, afinal a estação estava em boas condições, era visível que havia um cuidado com a edificação. Em frente à estação, havia um poste de luz com uma sacola de lixo pendurada, mais indícios do não abandono. Como não haviam residências tão próximas, provavelmente aquele lixo pertencia à estação (Figura 7).

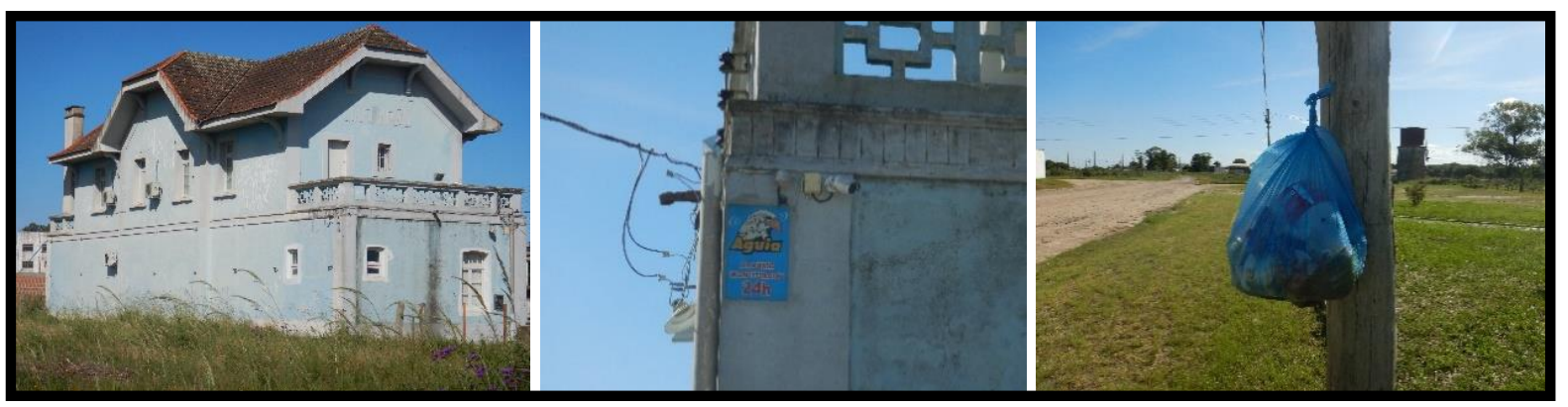

Figura 7: Conjunto de imagens do abandono não visível.

Fonte: Acervo da autora, 2019.

Havia uma estrada de terra em frente, por ali passavam carros, caminhões e pedestres. Ninguém olhava para a estação, parecia um lugar invisível. Atualmente funciona uma loja maçônica. No dia visitado, a edificação estava fechada, ninguém ocupando aquele espaço. Havia um abandono de pessoas, de movimento, de vida naquela ambiência. O prédio fechado sem aparência de abandono, estava abandonado.

\subsection{Abandonos de Estação Férrea}

As experiências de ir a campo nas cidades-gêmeas trouxeram sensações diferentes e peculiares. Em cada situação o sentimento e as impressões percebidas no local revelaram pistas que vão além do abandono material. Quanto à estação férrea de Rio Branco, no Uruguay, fica a sensação de que a história da linha férrea e da estação permanecem vivas na memória daquele lugar. Os trilhos encontram-se em todo percurso, nada foi retirado, o caminho pelos trilhos trazia energia ao local. Apesar da vegetação alta e dos animais circulando pelos trilhos, nada impedia que o trajeto fosse realizado.

No entorno da estação férrea havia movimento, era um local de passagem, um ponto de encontro de jovens, a moradia de um ex-ferroviário. A estação era convidativa, trazia uma energia que fazia permanecer, havia algum sentido que fazia percorrer ali, sentar e admirar o lugar. A presença do abandono material e visível da estação férrea, não interfere nas interações. Uma arquitetura do abandono que toca nossos olhares, mas também toca nossos 
sentidos, cria um movimento, um som, um tato que faz permanecer no local, propiciando um ambiente acolhedor e familiar (PALLASMAA, 2011, p.66).

Na estação de Jaguarão, no Brasil, percebe-se a ambiência de outra perspectiva. O abandono material não é presente, existe conservação, o cuidado com a edificação, que é visível para quem visita o local. Entretanto, é percebido um outro abandono, o abandono imaterial. O abandono que se sente, que perde o sentido simplesmente por estar ali, é um abandono que está oculto, velado. Este tipo de abandono é mais difícil de ser identificado, mas a partir de pequenos sinais eles podem ser percebidos. Como as cercas no entorno da estação, uma barreira física e emocional. A sensação da invasão, o ambiente não convidativo. Que vigia, controla, filma, que registra os passos de quem circula por lá. Há uma tensão e desconforto com a própria presença.

A estação férrea que era um ponto de encontro antigamente, perde seu sentido nos dias de hoje. Há forças que atuam em direções opostas, as que aproximam para ir até o local, para conhecer, desfrutar e estas mesmas forças que atuam para afastar, repelir, que fazem sentir o abandono na própria pele. O lugar perde sua significatividade, que segundo o conceito trazido por Martin Heidegger "cada lugar já é sempre o lugar de alguma coisa que há tempos permanece ali” (SARAMAGO, 2008 p.197). Quando se perde esse sentido, esse significado, atuam forças que nos afastam desse mesmo lugar. Não há pessoas circulando, não há interações, não há vida no lugar. Há um abandono encoberto, oculto, velado, mas que é sentido e nos confronta.

Deste modo, é que se identificam dois tipos de abandono nas estações férreas. Um é o abandono material, aquele que é visível. Pode ser identificado rapidamente pela sua aparência, são telhas quebradas, rachaduras na edificação, mofos, falta de elementos, estrutura danificada, dentre outros fatores. São as marcas do abandono na própria edificação, uma mutilação, retaliação. Está explícito o processo de arruinamento, de deterioração da obra. $\mathrm{O}$ segundo tipo é o abandono imaterial, daquele que é oculto, velado. É um abandono que é sentido, apresenta o abandono de forma sutil, mas que é sentido de maneira intensa. Os usos, as ocupações, os acontecimentos presenciados naquele lugar não se inserem no contexto da antiga estação férrea. Está lá por sua materialidade, mas o seu sentido está abandonado, esquecido, ignorado.

Os dois tipos de abandono relatados neste trabalho, necessariamente não apresentam relações diretas. Por exemplo, um abandono material não está ligado diretamente com um abandono de sentido. Não é porque um edifício está abandonado materialmente, que ninguém deseja ocupar aquele espaço, como pode-se perceber com a estação férrea de Rio Branco, que 
apresenta diferentes usos e sentidos no seu entorno. Assim como, uma edificação que possui um novo uso, não significa que o lugar será valorizado e ocupado, como visto na estação férrea de Jaguarão, que não havia movimentação, nem sentido naquela ambiência. Desta forma, o abandono pode ser interpretado de maneiras distintas e exige uma atenção devido sua complexidade. Uma vez que a aparência do abandono, às vezes pode apresentar mais vida a um lugar, do que uma edificação que não está abandonada.

\section{Conclusões}

Durante toda a trajetória das ferrovias, as estações férreas proporcionaram cenários de encontros que marcaram a vida de muitas gerações. Possuíam um papel importante para o desenvolvimento econômico e social, estabelecendo um vínculo com outras cidades e países, como é o caso do Brasil e o Uruguay. Entretanto, a extinção do transporte de passageiros eliminou o sentido que tinham as estações férreas. Aos poucos, ficaram esquecidas, sem perspectivas de recursos para sua conservação, tornando-se abandonadas.

Com um olhar atento e sensível aos encontros com os abandonos das estações férreas, tentamos apresentar a significância que essas edificações representam para quem convive naquele entorno. Percebemos que o modo de ocupar o espaço, os usos ou a ausência deles, nos levam às pistas para a análise sensitiva daqueles lugares. A prática de ir a campo explorar um território desconhecido nos afeta diretamente e nos faz pensar sobre as sensações que um lugar pode nos causar.

Os caminhos que nos levam ao abandono das estações férreas são complexos e podem ser de diversos tipos. Não há uma definição certeira ou generalizada para qualquer estação férrea abandonada, pois vai além do que é perceptível aos nossos olhos. O abandono também é sentido e para isso exige a presença no plano da experiência, onde são percebidas as potencialidades que um lugar pode gerar nos indivíduos.

Entretanto, os tipos de abandono trazido aqui não são classificatórios, muito menos categóricos. Cada experiência e pesquisa são únicas, podendo revelar outros modos possíveis de adicionar, cruzar, sobrepor, reinventar como pistas de um abandono. O abandono de estações férreas tem muitos caminhos para serem descobertos e analisados. Resta-nos estarmos atentos aos sinais desvendados pelo abandono. Observar a cidade através do olhar de uma cartógrafa, que olha o abandono como uma maneira de intervenção, potencializados pelos modos de fazer, sentir e vivenciar a cidade na contemporaneidade. 


\section{Referências}

DELEUZE, G. e GUATTARI, F. Mil Platôs. Capitalismo e esquizofrenia 2. Vol 1. Trad. Sob a direção de Ana Lúcia de Oliveira, Aurélio Guerra Neto e Célia Pinto Costa. São Paulo: Editora 34, 2011. 2 ed.

GEUX, G. $O$ síndrome de abandono. Trad. Sob a direção de Valerie Rumjanek. Rio de Janeiro: Record, 1973. (Edição Revista de "la nevrose d'abandon". 2a ed. Presses Universitaires de France).

IPHAE - Instituto do Patrimônio Histórico e Artístico do Estado da Secretaria da Cultura do Rio Grande do Sul. Patrimônio Ferroviário no Rio Grande do Sul. Inventário das Estações: 1874 -1959. In: [pesquisadoras CARDOSO, Alice; ZAMIN, Frinéia]. Porto Alegre: Pallotti, 2002.

IPHAN - Instituto do Patrimônio Histórico e Artístico Nacional. Dossiê de Tombamento do Conjunto Arquitetônico e Paisagístico de Jaguarão. Ministério da Cultura: IPHAN, Porto Alegre, 2010.

JACQUES, P. B. Breve histórico da Internacional Situacionista - IS. Vitruvius. 035.05, ano 3, abr. 2003. Arquitextos ISSN 1809-6298. Disponível em: https://www.vitruvius.com.br/revistas/read/arquitextos/03.035/696. Acesso em: 19 dez. 2019.

MARTINS, R. D. A ocupação do espaço na fronteira Brasil-Uruguai: a construção da cidade de Jaguarão. 2001. 280 f. Tese (Doutorado em Arquitetura) - Departament de Composició Arquitectónica, Escola Tècnica Superior D’Arquitectura, Universitat Politècnica de Catalunya, Espanha, 2001.

MUSSO, C. Las ciudades del Uruguay, su origen, evolución histórica y urbanística em el contexto nacional y macro regional y sus perspectivas de futuro. Montevideo: Facultad de Arquitectura. 2004. 382 f.

PALLASMAA, J. Os olhos da pele: a arquitetura e os sentidos. Trad. Técnica Alexandre Salvaterra. Porto Alegre: Bookman, 2011.

PASSOS, E; KASTRUP, V; ESCÓSSIA, L. Pistas do método da cartografia: Pesquisaintervenção e produção de subjetividade. Porto Alegre: Sulina, 2015.

ROCHA, E. Cartografias Urbanas. Revista Projectare, Pelotas, v.1, n.2, p. 163 - 173, 2008. ISSN 1518-5125 Disponível em: https://wp.ufpel.edu.br/projectare/artigos-projectare-2/. Acesso em 26 dez. 2019.

ROCHA, E. Arquitetura do abandono (ou uma cartografia nas fronteiras da arquitetura, da filosofia e da arte). 2010. 263 f. Tese (Doutorado em Arquitetura) - Programa de Pesquisa e Pós-Graduação em Arquitetura, Universidade Federal do Rio Grande do Sul, Porto Alegre, 2010.

SARAMAGO, L. A "topologia do ser": lugar, espaço e linguagem no pensamento de Martin Heidegger. Rio de Janeiro: Ed. PUC-Rio; São Paulo: Loyola, 2008. 
RELACult - Revista Latino-Americana de Estudos em Cultura e Sociedade

Revista Latinoamericana de Estudios en Cultura y Sociedad | Latin American Journal of Studies in Culture and Society V. 06, ed.especial, mar., 2020, artigo $n^{\circ} 1751$ | claec.org/relacult | e-ISSN: 2525-7870 